\title{
Study on Railway Disaster Monitoring and Warning System Based on Assessment of Landslide Stability
}

\author{
Zhifeng Liu \\ Jiangxi Province Key Lab for Digital Land, School of \\ Information Engineering \\ East China Institute of Technology \\ Nanchang, Jiangxi, China \\ Lzhifeng0904@163.com
}

\author{
Zhenhua Wei and Wei Xu \\ School of Software, East China Institute of Technology \\ East China Institute of Technology \\ Nanchang, Jiangxi, China
}

\begin{abstract}
With the rapid development of Chinese railway, the high-speed railway construction has also entered a period of rapid development. The harmfulness of natural geological disasters and accidents to running trains is greatly. They may cause the railroad movement to appear dangerous like as the rainstorm, the gale, the heavy snow, the landslide and so on. The contents of this research were carried out both at home and abroad. But the research of the disaster system of the geological landslide has not formed the available information system in our country. In view of needing the information technology of highspeed railway in China, the research work of the railway disaster monitoring and warning system (RDMWS) based on the landslide stability was carried out, including the overall design, detailed design, and some functions of the system. The system is mainly to achieve the three-dimensional geological model of dynamic loading, a model railway generate dynamic, threedimensional roaming visualization display, dynamic updating of the geological disasters, and disaster monitoring simulation work, and we achieved the stage results.
\end{abstract}

Keywords-Railway; Disaster; Landslide; Monitoring and warning system

\section{INTRODUCTION}

At present, along with the rapid development of Chinese railway, the high-speed railway construction has also entered a period of rapid development. With the construction of the new line of passenger dedicated line, intercity, high-speed railway, the train's velocity has reached $350 \mathrm{~km} / \mathrm{h}$. In the course of the high-speed train, natural disasters and accidents are harmful to the running $\operatorname{train}^{[1-2]}$. The rainstorm, strong wind, heavy snow, landslides and so on may cause the dangerous of running train. There are frequent casualties from all parts of the country that are causing casualties or damage to equipment. For example, on May 23, 2010 a train called k859 that was running to Jiangxi province (K699+700 meters) hit the collapse of the mountain that was caused by the days of heavy rains. As a result, the locomotive and machine after the 1 to 9 vehicle offline, the accident caused 19 people were killed, the line was interrupted. On April 7, 2001, China 30181 goods train running to the XinLan line $\mathrm{K} 36+515$ at the time overturn accident due to the resistance of natural disasters caused by winds. Such accidents as occurred, such as on April 12, 2010, a serious mountain landslide lead to northern Italy a running train derailment, the accident caused a total of more than 80 people dead and injured ${ }^{[3-5]}$.

In order to prevent the accidents caused by natural disasters, many countries are actively developing railway disaster prevention and safety monitoring system ${ }^{[6-8]}$. Based on the investigation of the railway geological disasters, the RDMWS based on the landslide stability is studied.

\section{FRAMEWORK FOR RDMWS}

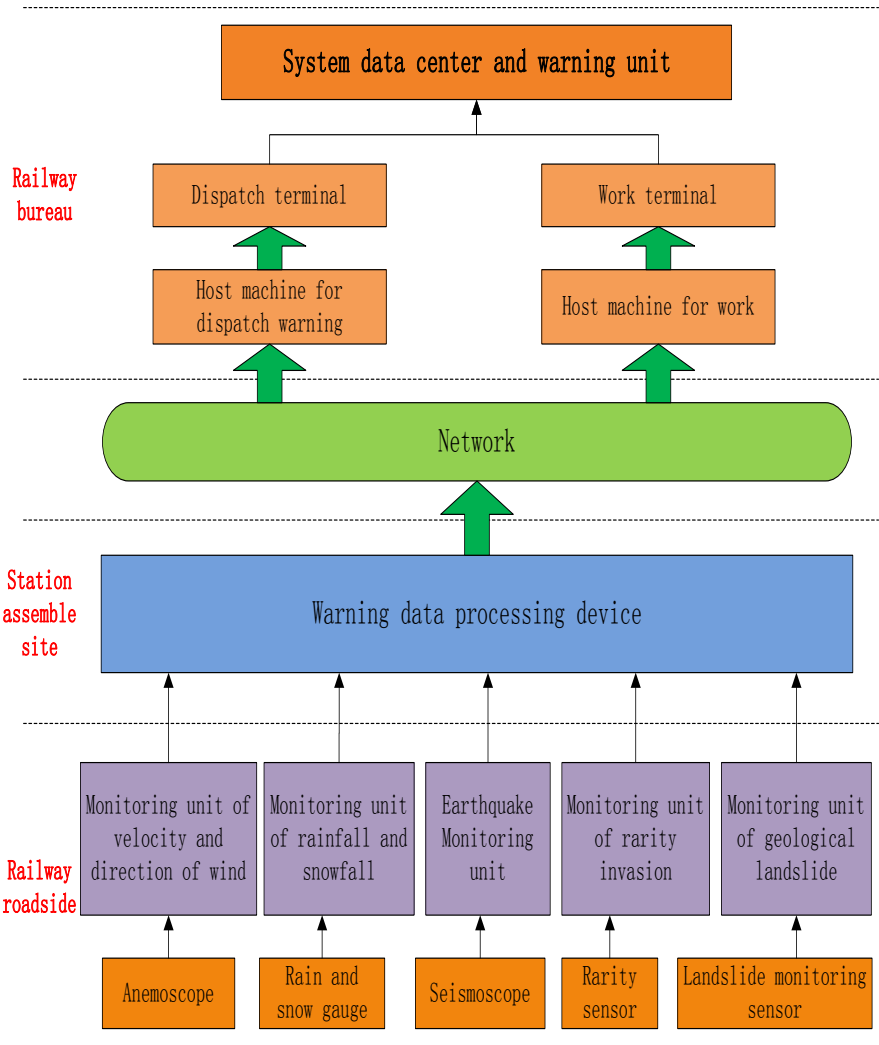

Fig.1 System structure diagram of RDMWS

Railway disaster prevention and safety monitoring system is the real-time monitor that can monitor the disasters, for example, the wind, the rain, the snow, the foreign body, the geological landslides and other hazards ${ }^{[9,10]}$. The system 
realizes distributed collection, centralized management and comprehensive analysis of the monitoring data. It can grasp dynamic disasters and constitute a security system for the railway transportation with the column control system, dispatching system, traction power supply system, integrated maintenance system and emergency rescue system. The structure of the system is shown in Fig.1. This paper focuses on the geological landslide disaster monitoring and visualization monitoring display. The data from acquisition unit is uploaded to the station monitoring unit, and then through the network uploaded to the processing equipment of Railway Bureau. The data can be used to analyze, store and generate the warning. At the same time, the data is stored in the data center and used to analyze.

\section{ANALYSIS OF THE RDMWS’ DATA SOURCE}

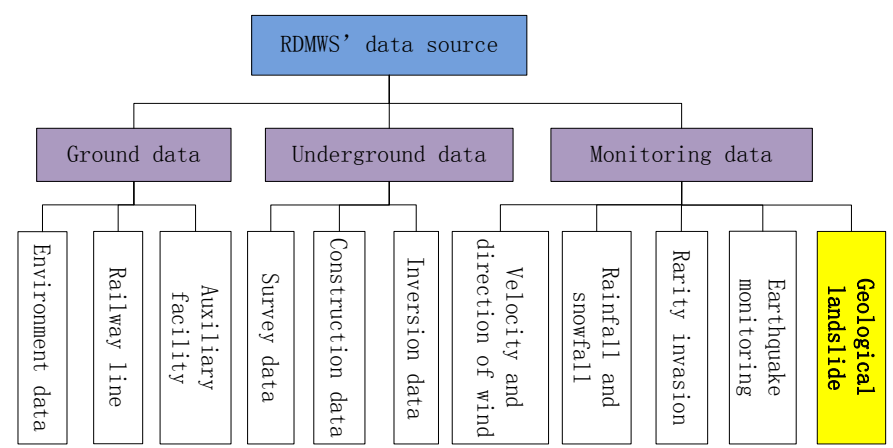

Fig.2 Data source of RDMWS

The data of RDMWS is composed of three parts that are showed in Fig.2. Firstly, the surface of the above ground includes environmental data, railway line data and railway auxiliary facilities data, called the ground data. Secondly, the 3 dimension geological data which is underground geological hazard monitoring section, this data is called underground data. Thirdly, it is the geological hazard monitoring data which is mainly from real-time data collected by geological disaster monitoring instrument. These three kinds of data are mainly used for ground and underground 3D geological body modeling, disaster monitoring and early warning. We can use the data to realize real-time on-line monitoring of geological disasters.

\section{THE SCHEME OF DATA ACQUISITION}

The main data stream of RDMWS is shown in Fig.3. The data source of the system data acquisition preprocessing module mainly comes from two parts. The first part of the data which is from the sensor placed in the potential disaster, is transmitted to the terminal using communication network, and is interpreted, processed, and analyzed to achieve real-time display and storage. The other part of the data is the threedimensional model data from the roaming module. They include the railway model, the roadbed model and the disaster body model, etc. The two kinds of data are merged together through the data interface. They can be formed to the intuitive data for visualizing, and they can be displayed on the monitor. The data source of the "intelligent modeling model of the three-dimensional geological disaster" is from the parameterized railway lines including the information of the curve, the slope, the bridge, the tunnel and so on. The threedimensional railway model can be established automatically through the parameterized intelligent algorithm. The data source of the "monitoring and warning model of the threedimensional geological disaster" is from the sensor of the potential disaster bodies in the data acquisition model. The "three-dimensional navigating model" is the window for showing the basic information of the railway obviously, and provides the basic data for monitoring and warning.

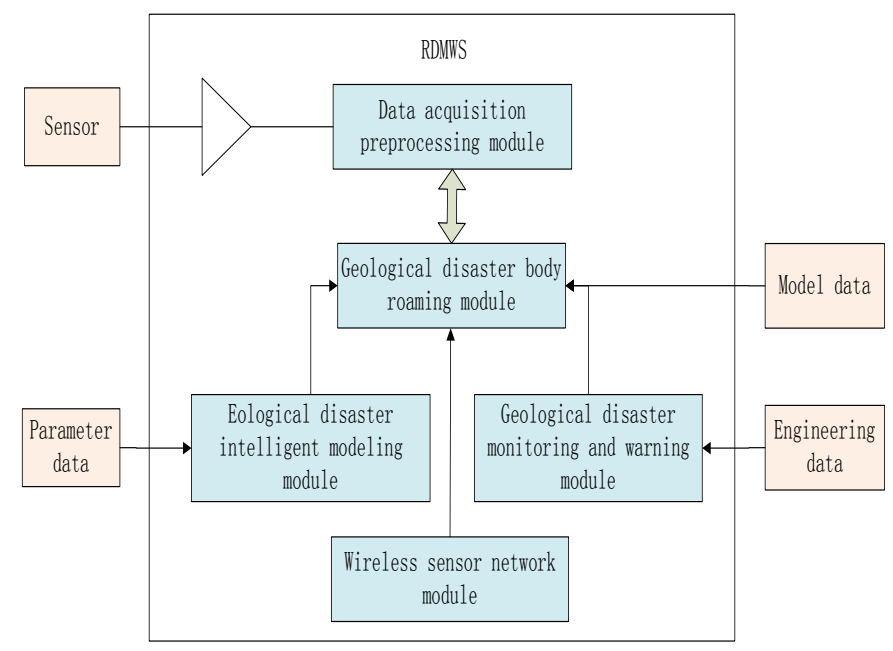

Fig. 3 Data flow of the RDMWS

As shown in the Fig.3, the system data source mainly includes four parts. The acquisition method of each part is stated as following.

\section{(1) Sensor data}

The sensor data are mainly from the geological disaster monitoring and warning sensors. The included data are related to the laid hardware. The hardware acquisition data related to this system mainly include the displacement transformation data of the side slope surface, the inside displacement data of the side slope soil body, the

(2) Parameter data

The parameter data are mainly from LKJ database which is the domestic railway dispatching system at present, using for describing the railway running parameter data, mainly including the railway roadbed type (embankment, cutting, bridge, tunnel etc.), the railway slope (upslope and angle, downgrade and angle), the corner data (related information of the railway turn) and so on.

(3) Engineering data

The engineer data are mainly used for three-dimensional modeling. The important data for establishing threedimensional geological model include the bedrock surface data and the super stratum subface (the potential landslide surface) data, which must be obtained because the two kinds of data are very important to the hardware laying, threedimensional modeling, the landslide monitoring and so on. There are two main acquisition types. One is selecting and handling through the data reserved through the engineering investigating, detecting, and constructing processes and so on. 
The other is detecting using the geophysical prospecting method such as geological radar. The geological disaster data can be acquired through the above types and provide the basic data source for detecting the geological disaster.

\section{(4) Model data}

The model data are generated mainly through the threedimensional modeling tools after modeling using the parameter data and the engineering data. The modeling tools should include data preprocessing tool, graphic processing tool, body surface modeling tool and three-dimensional model cutting tool. There are proven techniques of the above modeling tools at home and abroad.

\section{SOFTWARE SYSTEM DESIGN}

This system will include the following five modules, which are the data acquisition preprocessing module, the geological disaster intelligent modeling module, the threedimensional geological roaming module along the railway, the wireless sensor network module and the real-time monitoring and warning module of the geological disaster. They are shown in Fig.4.

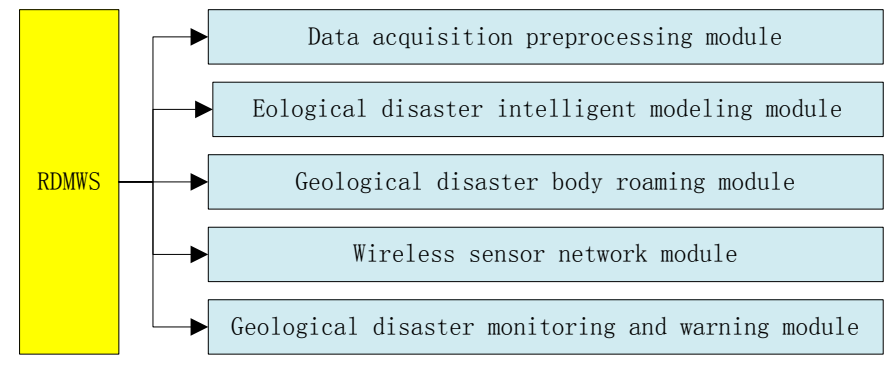

Fig.4 Architecture of RDMWS

The data acquisition preprocessing module, of which the main function is obtaining the basic data for RDMWS, provides the basic data source for the geological disaster monitoring and warning by acquiring the geological disaster information along the railway collected by the remote sensor through the wireless network.

The geological disaster intelligent modeling module mainly generates the three-dimensional geological disaster zone model using the engineering geological data along the railway, provides the universal data interface to achieve importing the existing engineering geological map (vector) data or the model data automatically, to realize modeling and updating the railway line data and the zone railway construction (roadbed, bridge, tunnel etc.) data automatically, and offers the data source for three-dimensional geological roaming module.

The three-dimensional geological roaming module displays the over ground and the under ground situation of the roaming section on line mainly through dynamic dispatching the geological disaster zone model and the railway line model.

The wireless sensor network module obtains the real-time parameter of the monitored disaster body through selecting the disaster zone, locating and laying the wireless sensor via the three-dimensional geological roaming module. The parameters acquired from the wireless sensor network module are taken as the data source for the monitoring and warning module of the geological disaster to provide the data information. Thus, the monitored geological disaster body can be monitored timely and warned dynamically. The monitoring and warning module of the geological disaster, which is a client, shows the warning information to the users according to the default classification rank (or degree).

\section{ANALYSIS AND EVALUATION OF THE LANDSLIDE STABILITY}

The main goal of the landslide stability analysis and evaluation is evaluating the steady state of the present landslides, analyzing the possible transformation growing trend with the time lapse. The landslide materials, which are the gravelly soil with loose structure, distribute equably in the space. The transfer coefficient method is used to calculate the landslide stability. The computational formula (1) is as following:

$$
\begin{gathered}
F s=\frac{\sum_{i=1}^{n-1}\left(R i \prod_{j=1}^{n-1} \Psi i\right)+R_{n}}{\sum_{i=1}^{n-1}\left(T i \prod_{j=1}^{n-1} \Psi i\right)+T_{n}} \\
\text { Where: } \\
\Psi_{i}=\cos \left(\alpha_{i}-\alpha_{i+1}\right)-\sin \left(\alpha_{i}-\alpha_{i+1}\right) \cdot \tan \varphi_{i} \\
R_{i}=N_{i} \cdot \tan \varphi_{i}+C_{i} L_{i} \\
N_{i}=Q_{i} \cdot \cos \alpha_{i} \\
T_{i}=Q_{i} \cdot \sin \alpha_{i}
\end{gathered}
$$

$F s$-landslide stability coefficient

$Q_{i}$ - gravity of the $\mathrm{i}^{\text {th }}$ slip mass $(\mathrm{KN} / \mathrm{m})$

$R_{i}$-cohesion stress of the $\mathrm{i}^{\text {th }}$ block sliding surface $(\mathrm{KN} / \mathrm{m})$

$N_{i}$-normal component force of the $\mathrm{i}^{\text {th }}$ block sliding surface $(\mathrm{KN} / \mathrm{m})$

$\varphi_{i}$-internal friction angle of the $\mathrm{i}^{\text {th }}$ block sliding surface soil $\left(^{\circ}\right)$

$C_{i}$ - cohesion of the $\mathrm{i}^{\text {th }}$ block sliding surface (KPa)

$L_{i}$ - length of the $\mathrm{i}^{\text {th }}$ block sliding surface $(\mathrm{m})$

$T_{i}$-sliding component force of the $\mathrm{i}^{\text {th }}$ block sliding surface $(\mathrm{KN} / \mathrm{m})$

$\alpha_{i}$-inclination angle of the $\mathrm{i}^{\text {th }}$ block sliding surface (o)

$\psi_{i}$ - transfer coefficient of the residual thrust transferring from the $i^{\text {th }}$ block to the $(i+1)^{\text {th }}$ block

The minimum safe coefficient table, which is shown in table 1 , is designed through the landslide stability coefficient according to the above formulas. All the parameters in table 1 
can be obtained through the assistance of the displacement sensor.

TABLE I. ANTI-SLIDING STABILITY MINIMUM SAFE COEFFICIENT TABLE OF THE RAILWAY GEOLOGICAL LANDSLIDE

\begin{tabular}{|c|c|c|c|c|}
\hline $\begin{array}{c}\text { Rank } \\
\text { Running } \\
\text { condition }\end{array}$ & I & II & III & IV 、 V \\
\hline $\begin{array}{c}\text { Normal } \\
\text { condition }\end{array}$ & 1.30 & 1.25 & 1.20 & 1.15 \\
\hline Sleet weather & 1.20 & 1.15 & 1.10 & 1.05 \\
\hline
\end{tabular}

The above parameters of hazard evaluation are mainly from the real-time data of geological exploration and sensor data collection. The real-time data and the geological data are used to update the three-dimensional model dynamically. Besides, the landslide stability coefficient and the threedimensional model are contrasted strikingly to provide important means for disaster monitoring and warning.

6. Research achievements of the three-dimensional model updating and roaming

According to the general design, the dynamic updating and roaming functions of the three-dimensional railway model have been developed primarily. Fig 5 shows four frame images, in which the dynamic updating of the roadbed, the rail, the crosstie and so on. The terrain model is extracted dynamically with the advancing route. The current model is about $600 \mathrm{M}$. The designed train velocity per hour is $300 \mathrm{~km} / \mathrm{h}$. The practical application showed that the system runs smoothly and displays realistically.
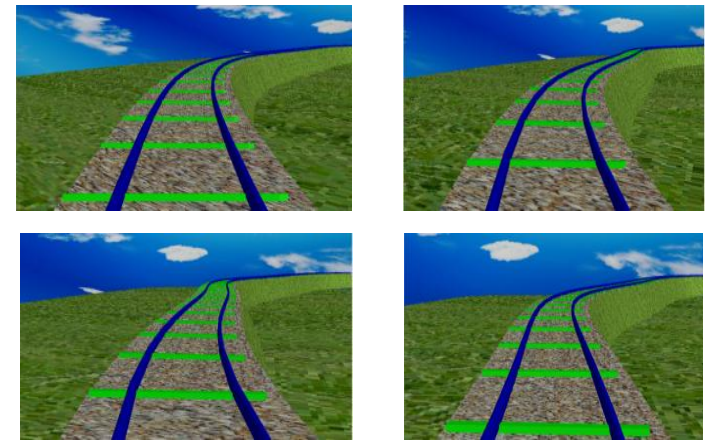

Fig.5 Roaming effect of the simple railway model at different positions
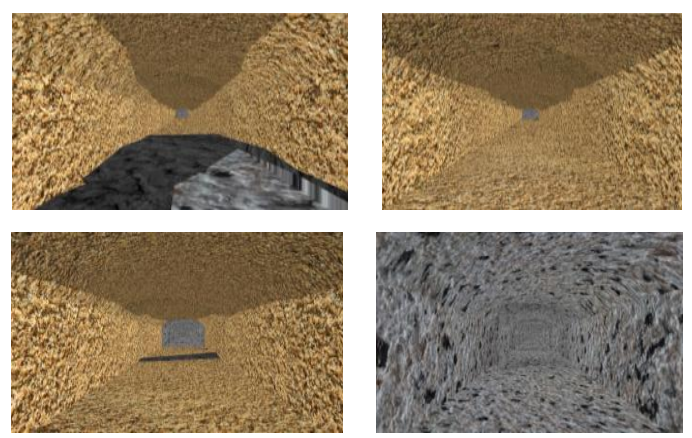

Fig.6 Roaming effect inside the tunnel
Fig.6 simulates the serial images cut out during the roaming process based on the geological transformation in the tunnel. The experiments demonstrated that the threedimensional roaming model is limited to the model total size. When the model is bigger than $800 \mathrm{M}$, the running speed will be influenced. The roaming function has been finished, but the functions of data optimization, vacation disposal etc. need further improving and supplying.

\section{CONCLUSION}

As the pre-research of RDMWS based on the landslide stability evaluation, the periodical achievements embody the idea of the general design, verify the feasibility of the system design, and provide auxiliary means for the monitoring and preventing of the railway landslide disaster. Thus, the human input of disaster prevention can be reduced, the early warning alarm will be obtained automatically, the work efficiency can be improved and the potential dangers of the personnel live view will be reduced. The most important thing is to be able to provide additional protection for safe operation of the railway.

\section{Acknowledgment}

This work was funded by Jiangxi Province Key Lab for Digital Land(No.DLLJ201311) and Doctoral Fund Project of East China Institute of Technology (No.DHBK201101 and No.DHBK201102).

\section{References}

[1] Sun Chengxin. Research and Implementation of Disaster-Prevention Monitoring and Early-Warning System for the Railway[D]. Lanzhou Jiaotong University Master Degree Thesis, 2014.

[2] Wang Shuang. Research and Implementation of High-speed Rail Disaster Prevention and Security Intelligence Monitoring Unit[D]. Lanzhou Jiaotong University Master Degree Thesis, 2014.

[3] Stéphane Sanquer, Christian Barré, Marc Dufresne de Virel and LouisMarie Cléon. Effect of cross winds on high-speed trains[J].Journal of Wind Engineering and Industrial Aerodynamics,2004,92, pp.535-545.

[4] Makoto Shimamura. A new method in Wind forecasting and operation in the Railway Safety Management, Journal of the EasternAsin Society, 1995,11 .

[5] Hppmann U, Koenig S, Tielkes T, etc. A short-term strong wind prediction model for railwayapplication: design and verification. Journal of Wind Engineering and Industrial Aerodynamics,2002,90(10), pp.1127-1134.

[6] Tielkes Th,Matschke G, Schulte-Werning B , etc. A short term wind warning system to counteract the effects of cross winds wind on high speed trains. PSAM5-Probabilistic Safety Assessment and Management. Tokyo: Universal Academy Press, 2000, pp.2047-2053.

[7] Kobayashi N, Shimamura M. Study of a Strong Wind Warning System. JR EAST Technical Review,2002. pp.61-65.

[8] Shimamura M. Study on strong wind predicting technique for safety management of train operation.Japanese Railway Engineering, 1995,134(9), pp.15-18.

[9] Wang Dawei. Realization and Software Simulation of High-Speed Railway Disaster Prevention System's Station Computer Layer. Southwest Jiaotong University Master Degree Thesis,2012.

[10] Bai Guangzheng, Guo jin, Yang yang, Zhou Junhui, Wang Dawei. Software Design of High-speed Rail Disaster Prevention and Security Monitoring System[J].Chinese Railways,2011(9), pp.9-12. 